\title{
Prioritization of areas in China for the conservation of endangered birds using modelled geographical distributions
}

\author{
GUOJUN CHEN and A. TOWNSEND PETERSON
}

\begin{abstract}
Summary
We developed distributional models for 90 threatened bird species in China, and used heuristic complementarity algorithms to prioritize areas for conservation. The pixel-based area selection prioritized 20 areas for protection, which covered all species analysed. Area selecting for endangered species based on the existing biosphere reserve system included only 37-62 species in eleven reserves, leaving 28-53 species unprotected. We employed algorithms for area selection based on species richness and rarity and obtained two views of a most efficient reserve network. We used the distributional hypotheses to identify additions to the reserve system that would improve its effectiveness substantially. The pixel-based area selection approach includes species much more efficiently on a per-area basis, and thus offers exciting perspectives for improved protection of the country's endangered avifauna.
\end{abstract}

\section{Introduction}

Geographical information system applications in conservation biology have proceeded in two general directions. The first consists of developing algorithms to predict species' geographical distributions. Species' ecological niches are characterized in multivariate environmental space, and geographical areas fitting these conditions are then taken as the predicted distribution, filling gaps created by uneven sampling (Nix 1986, Walker and Cocks 1991, Carpenter et al. 1993, Sperduto and Congalton 1996). The second direction is prioritizing areas for conservation, as exemplified by Gap Analysis and other applications (e.g. Daniels et al. 1991, Russell-Smith and Bowman 1992, Bojórquez-Tapia et al. 1995, Harrison and Martinez 1995, Kiester et al. 1996), in which distributional information is integrated into strategies for reserve portfolio design. Integrated, these two efforts can provide a strong basis for decisions on geographical priorities for conservation (Peterson et al. 2000).

The Red List of Threatened Species (IUCN 2000) includes 128 bird species that occur in China, 85 of which are listed as Critically Endangered, Endangered, or Vulnerable, and 28 of which are endemic to China. Many efforts have focused on conservation of these species and their habitats, but natural habitats across vast areas of the country have already been disturbed. Indeed, it is difficult to find undisturbed habitats and landscapes in China because of a burgeoning human population and rapid economic development. The application of new, 
quantitative methodologies in the region may be useful for addressing the challenge of preserving biological diversity and landscape in this region more effectively.

In this paper, we bring new tools from biodiversity informatics and quantitative geography to bear on the challenge of prioritizing areas in China for conservation action. Geographical distributions of endangered bird species are modelled, foci of species richness identified, and prioritizations assembled based on the maximum complementarity among areas or manual representation approaches of rare species. These approaches produce defendable, quantitative prioritizations, and offer a new perspective on conservation strategies in the region.

\section{Methods}

\section{Distributional data}

This study concentrates on 90 of the 128 species of threatened or endemic birds found in China (IUCN 2000), falling into the categories of Critically Endangered (four species), Endangered (seven species), Data Deficient (one species), Vulnerable (59 species), and lower risk but endemic (16 species), and protected birds for China (three additional, G. Chui pers. comm). We assembled sets of occurrence points from the scientific literature (Salvadori 1895, Peters 1940, Cheng 1979, 1987, Meyer de Schauensee 1984), and via the kind collaboration of BirdLife International (M. Crosby pers. comm.). We obtained 3-55 unique occurrence points per species. Textual geographical references were converted to latitudelongitude pairs by direct consultation of 1:200,000 maps. When species had more than one distributional area (e.g. breeding and wintering ground) within China (two cases), we treated them separately and weighted them equally in our analyses. For the remaining 38 threatened species, fewer than three occurrence records were available, and so these species were excluded from analysis.

\section{Geographical data}

We obtained base geographical data coverages from ESRI (1996). We used 23 variables: snow cover (low and high); annual, January and July precipitation (low and high); annual, January and July temperature (low and high); land use; geomorphology; solar radiation (low and high); human population; soils; vegetation; morphological structure; and frost-free period. Tests of the effects of inclusion and exclusion of particular variables (e.g. land use) were used to detect sensitivity in the result (Peterson and Cohoon 1999). We converted data coverages into ASCII raster grids using ArcView (version 3.1), and deposited them at the Biodiversity Species Workshop (BSW; http://biodi.sdsc.edu) facility as base coverages. Covering all of China, these base data sets are now publicly available for other applications (Chen and Peterson 2000).

\section{Modelling}

The fundamental ecological niche of a species, defined here as the conjunction of ecological conditions within which it is able to maintain populations without 
immigration (Grinnell 1917), can be depicted as a polyhedron or polyhedrons in multidimensional ecological space (MacArthur 1972). Several approaches have been used to approximate fundamental ecological niches of species, including BIOCLIM (Nix 1986) and logistic multiple regression and generalized linear modelling (Austin et al. 1990). Here, we employ the Genetic Algorithm for Ruleset Prediction (GARP), which includes these methods, among others, in an iterative, machine-learning approach (Stockwell and Noble 1992, Stockwell and Peters 1999). Individual algorithms are used to produce component "rules" in a broader rule-set, and hence portions of the landscape may be identified as inside or outside of the niche based on different algorithms. GARP therefore represents a superset of other approaches, and should generally have greater predictive ability than any one of them. Extensive testing of GARP has indicated excellent predictive ability for species' geographical distributions (Peterson and Cohoon 1999, Peterson 2001, Peterson et al. 2001, 2002). Indeed, recent sensitivity analyses addressing the ability of GARP to provide statistically robust distributional predictions indicated that 10-20 occurrence points are sufficient to achieve $90 \%$ of maximum predictive accuracy in almost all species (Stockwell and Peterson 2001a).

GARP results were output in the form of ASCII raster grids and imported into ArcView GIS (version 3.2) for analysis. Grids were reclassed to binary coverages, with o representing absence and 1 representing presence. In 77 cases, disjunct areas of overprediction, usually owing to historical effects in limiting species' geographical distributions (Peterson et al. 1999), were eliminated by taking the intersection of the crude GARP prediction and a polygon indicating the known geographical limits of the species' distribution (Peterson et al. 1999). Ideally, model results would have been tested with field inventories; however, few or no studies presented single-site inventory data in a convincingly complete form for Chinese localities.

\section{Analysis}

For the richness-based complementarity analyses, we summed predicted distributions to create a surface of predicted species richness (Peterson et al. 2000). We identified areas as groups of adjacent pixels with uniform species composition. The first priority area was identified as the area with highest numbers of cooccurring species. We identified and eliminated species present in this first area, and summed the remaining species. The area of maximum species richness based on this reduced set of species was taken as the second priority area. We continued this procedure of summing distributional maps of remaining species until the highest species richness was of single species (Peterson et al. 2000). We also applied a rarity based algorithm (Csuti et al. 1997). Here species richness is weighted by the multiplicative inverse of range-size (rarity), and area selected so as to maximize the sum of the weighted richness values.

We also considered the 19 existing biosphere reserves across China (http:// www.unesco.org/mab/wnbr.htm) to place our results in a more practical context. These biosphere reserves are Baishuijiang, Bogeda, Changbaishan, Dinghushan, Fanjingshan, Fenglin, Gaoligong Mountain, Huanglong, Jiuzhaigou Valley, Maolan, Nanji Islands, Shankou Mangrove, Shennongjia, Tianmushan, Wolong, 
Wuyishan, Xilin Gol, Xishuangbanna, and Yancheng, ranging from 4,284 to $1,077,450$ ha in size. We evaluated them against the above analysis to determine their effectiveness. After tallying species occurring in each area by eye in ArcView, we chose the protected area richest in bird species as the first one to enter into the heuristic system, eliminated those species from consideration, and identified further priority areas based on the remaining species and repeated the steps mentioned above.

We used two assumptions regarding species distributions to decide whether or not a species is found in a particular reserve. First, we tallied species' presences no matter how large their distributions were within a reserve ("any-occurrence"). In the second assumption, we considered a species as present in a reserve only if it was predicted as present in more than half of the reserve ("range-centre"). We prioritized the species left unprotected under each assumption to identify important area additions to the existing reserve system.

\section{Results}

\section{Distributional predictions}

The 90 species in this study showed a diversity of geographical patterns, ranging from broadly to narrowly distributed (Figure 1). For example, White-tailed Eagle Haliaeetus leucogaster and Baikal Teal Anas formosa were predicted to have ample distributions across the country: the former is predicted to be found in 13 of the 19 existing reserves, and the latter in six. In contrast, other species (e.g. Chinese Crested Tern Sterna bernsteini, Western Tragopan Tragopan melanocephalus) were predicted to have micro-scale distributions; these species are predicted to be present in a single reserve or no reserve.

\section{Analysis}

Based on the "any-occurrence" assumption, among existing biosphere reserves, Wolong was predicted to hold 23 species, and therefore entered first in the prioritization. Dinghushan was entered second in the system with 16 species, of which 11 were new to the system (i.e. not also in Wolong). Gaoligong entered third, with nine species new to the system. Next in order were Xilin Gol (adding six species), Tianmushan (four species), Jiuzhaigou (three species), Fenglin (two species), and Changbaishan, Bogeda, Shankou Mangrov, and Yancheng, each of which added single species (Table 1 ). Therefore, among existing protected areas and based on any occurrences, 62 of the 90 endangered species are protected (Figures 2a, 3). A similar area selection using the range-centre assumption became asymptotic at 37 species in 10 reserves, with areas in the following order: Jiuzhaigou (15 species), Dinghushan (adding eight species), Tianmushan (four species), Xilin Gol (three species), Wolong (two species), and Wuyishan, Shennongjia, Maolan, Fenglin and Changbaishan (each adding one species) (Figures $2 b, 3)$.

Assessing the avifauna without considering existing protected areas (Figure 4), an area in southernmost Sichuan Province (centre $102.8^{\circ} \mathrm{E}, 27.0^{\circ} \mathrm{N}$ ) was predicted to hold 20 of the 90 species (Table 1). A second area along the western Heilongji- 


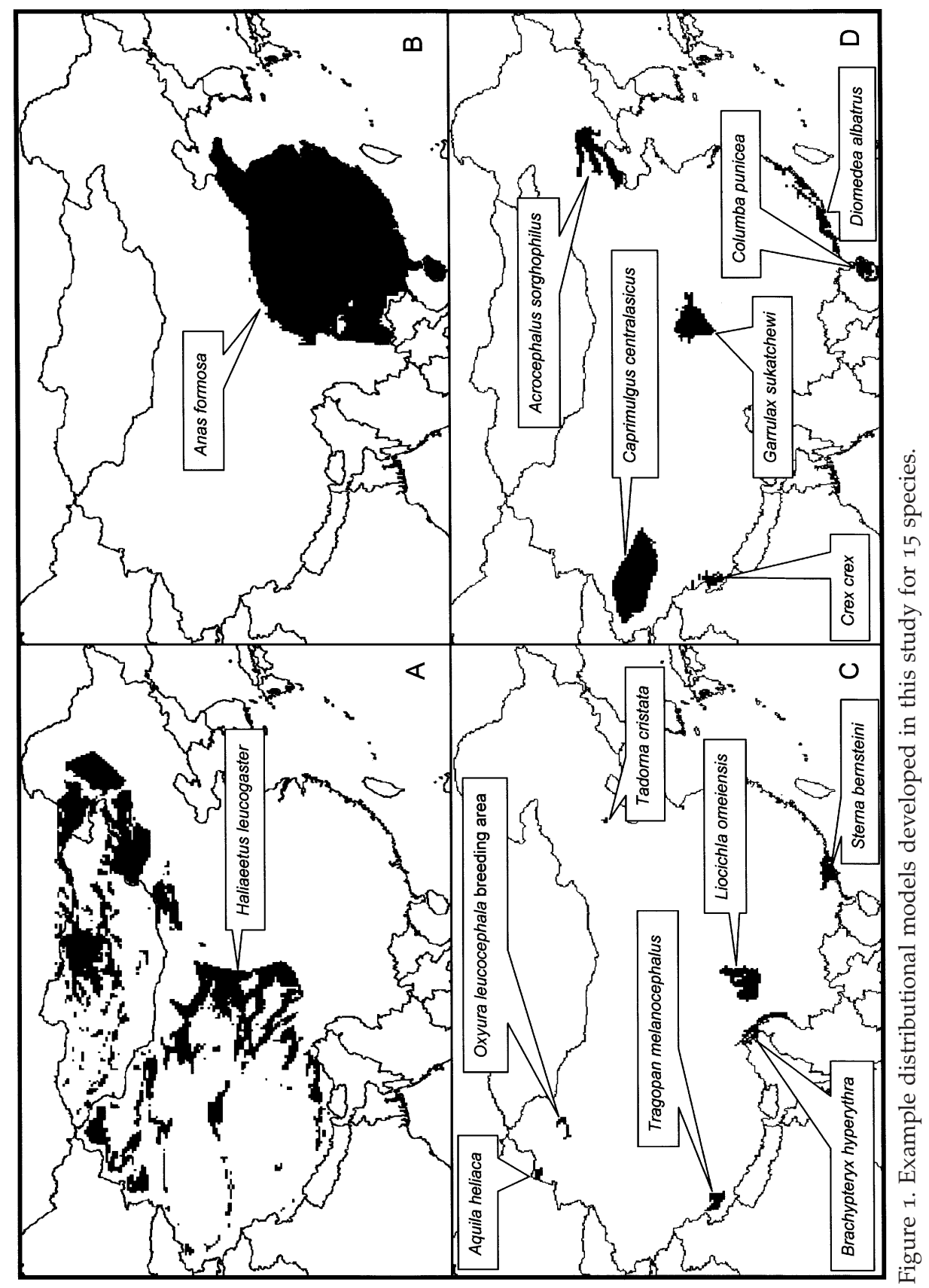




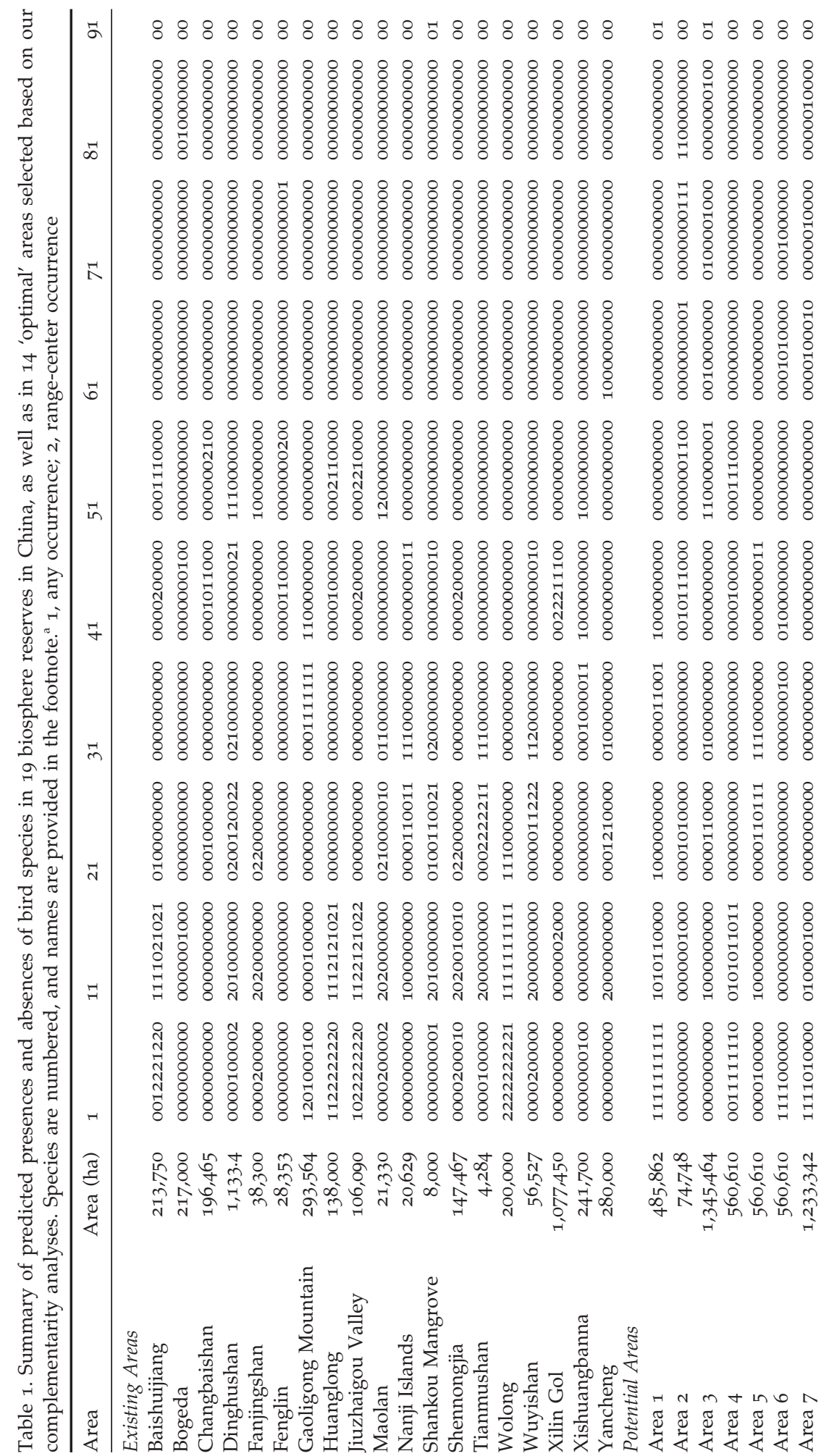




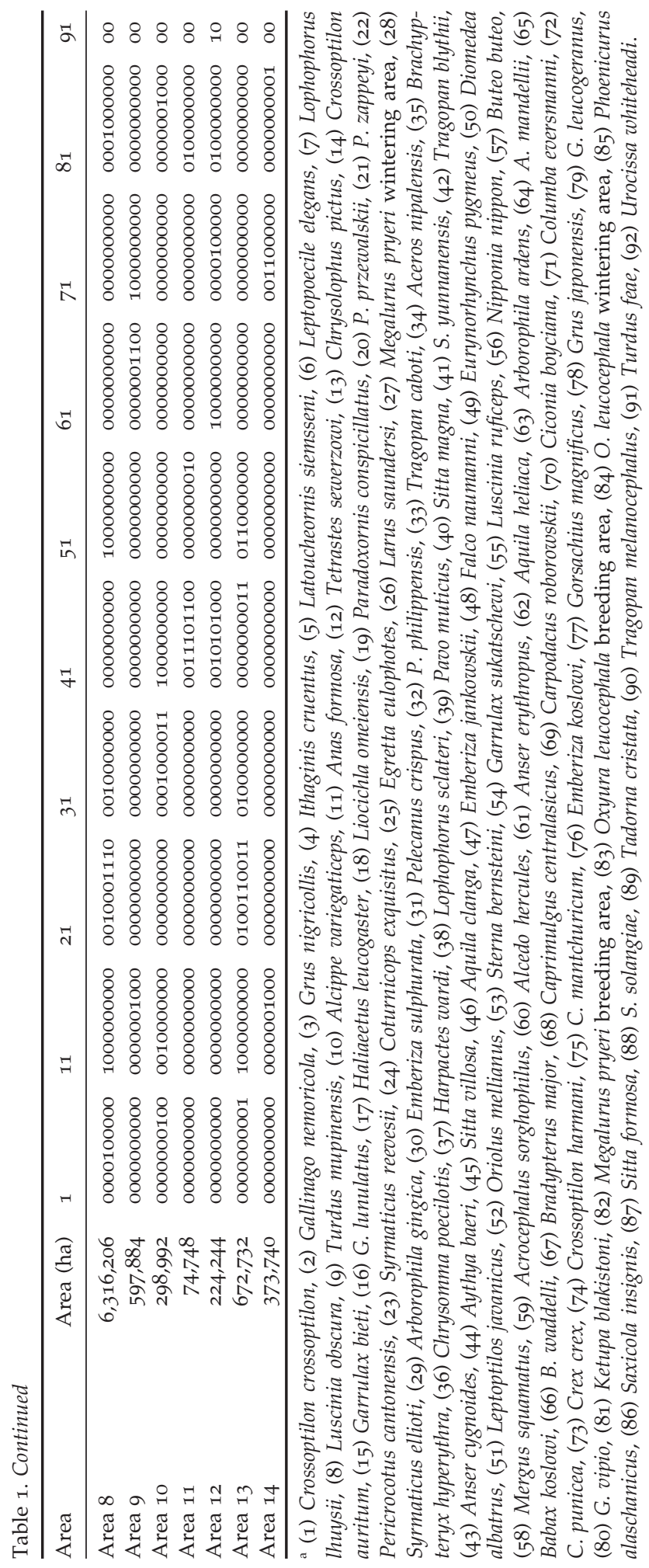




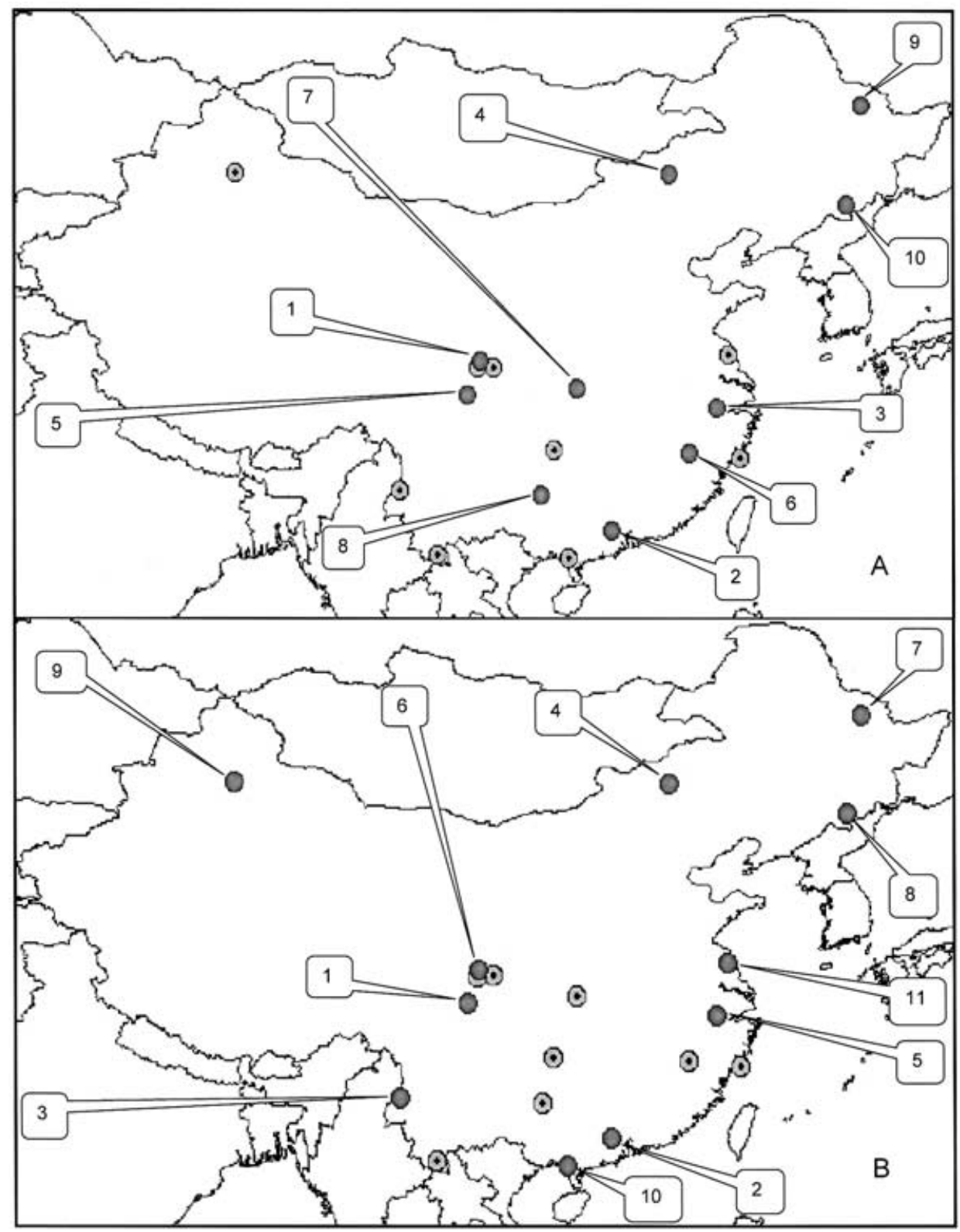

Figure 2. Prioritizations of existing reserves, with numbers corresponding to order of conservation priority: (A) for existing reserves, based on range-centre assumption; and (B) for existing reserves, based on any-occurrence assumption. Dotted circles indicate reserves not included in the priorization based on inability to add species to the system. 


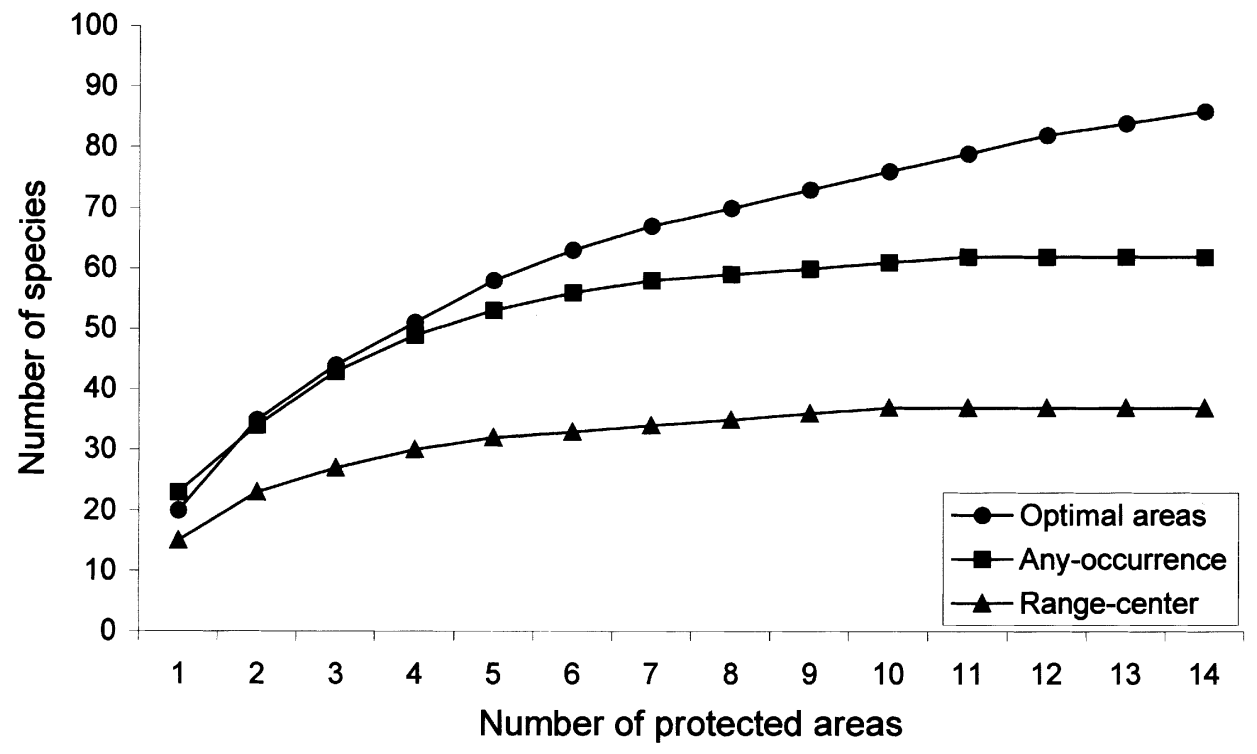

Figure 3. Accumulation of species in area selection analyses of existing reserves and of pixels (i.e. without regard to existing reserves) across China.

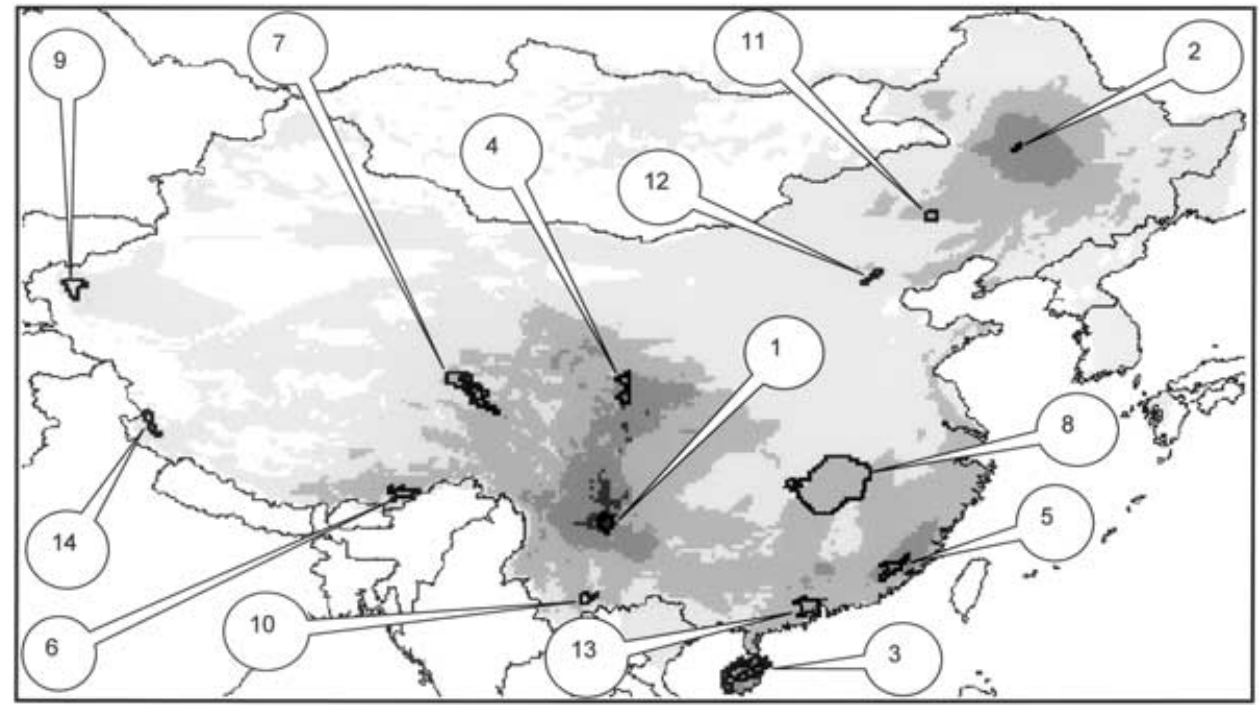

Figure 4. Richness map for the 90 species and selected pixel-based areas. White indicates species richness of $1-5$, light grey $6-10$, medium grey $11-15$, and dark grey $>16$. Dark lines indicate pixel-based potential protected areas, and numbers correspond to order of conservation priority. 
ang-northwestern Jilin border (centre $123.3^{\circ} \mathrm{E}, 46.6^{\circ} \mathrm{N}$ ) held 15 species new to the prioritization. A third site in northern Hainan Province (centre $109.9^{\circ} \mathrm{E}, 19.0^{\circ} \mathrm{N}$ ) added nine species to the system. Succeeding areas were southernmost Ganshu Province (seven species), southern Fujian Province (seven species), south-eastern Tibet (five species), southern Qinghai Province (four species), southern Hubei, north-eastern Hunan, and north-western Jiangxi (three species), westernmost Xinjiang Province (three species), southern Yunnan Province (three species), eastern Nei Mongol Province (three species), western Beijing and eastern Hebei Province (three species), southern Guangdong Province (two species) and westernmost Tibet (two species). The area selection ended at iteration 15, in which the six remaining species (Liocichla omeiensis, Brachypteryx hyperythra, Aquila heliaca, Oxyura leucocephala breeding area, Phoenicurus alaschanicus and Tadorna cristata) did not co-occur. Therefore, this area-selected system held 86 species in 14 areas, and 20 areas were identified that included all 90 species (Figure 3). Interestingly, accumulation of species in existing reserves under the "any-occurrence" in biosphere reserves assumption equalled the no-reserve approach through the fourth iteration; thereafter, however, accumulation of species in the no-reserve system outstripped that in the existing reserve system.

While assessing the avifauna using a rarity-based approach, without considering existing protected areas, an area in Hebei Province was predicted to hold five of the 90 species. A second area in southern Yunnan Province held eight species new to the prioritization. A third site in northern Hainan Province added 11 species to the system. Succeeding areas were north-western Xinjiang Province (two species), northern Xinjiang Province (one species), western Tibet (two species), eastern Tibet (10 species), southern Guangdong Province (seven species), southern Ganshu and northern Sichuan Provinces (12 species), Sichuan Province (four species), south-western Heilongjinag and northern Jilin Provinces (nine species), western Xinjiang Province (three species), eastern Nei Mongol and northern Liaoning Provinces (three species), eastern Hunan and western Jianxi Provinces (five species), western Beijing and eastern Hebei Province (three species), Qinghai Province (three species), southern Tibet (two species), and south-western Guizhou Province (two species).

Finally, to assess the 55 species not included in existing reserves under the rangecentre assumption, we selected areas for just those species to identify the most critical additions to the existing reserve network (Figure 5). An area in north-eastern China (centre $123.5^{\circ} \mathrm{E}, 46.2^{\circ} \mathrm{N}$ ) was predicted to hold 8 of these 55 species; a second area in western Yunnan Province added eight species to the prioritization; and a third site in Hainan Province added seven species to the system. Succeeding areas were in southern Qinghai Province (five species), Sichuan Province (four species), south-eastern Guangdong Province (three species), western Beijing and eastern Hebei Province (three species), western Xinjiang Province (three species), Nei Mongol, Ganshu, Qinghai and Ningxia provinces (two species), south-eastern Tibet (two species) and western Tibet (two species). The area selection ended at iteration 13, in which the six remaining species (Aquila heliaca, Brachypteryx hyperythra, Oxyura leucocephala breeding and wintering areas, Sitta formosa, and Tadorna cristata) did not co-occur. While assessing the 55 species not included in existing reserves under the range-centre assumption with species-richness method, we obtained almost the same results. 


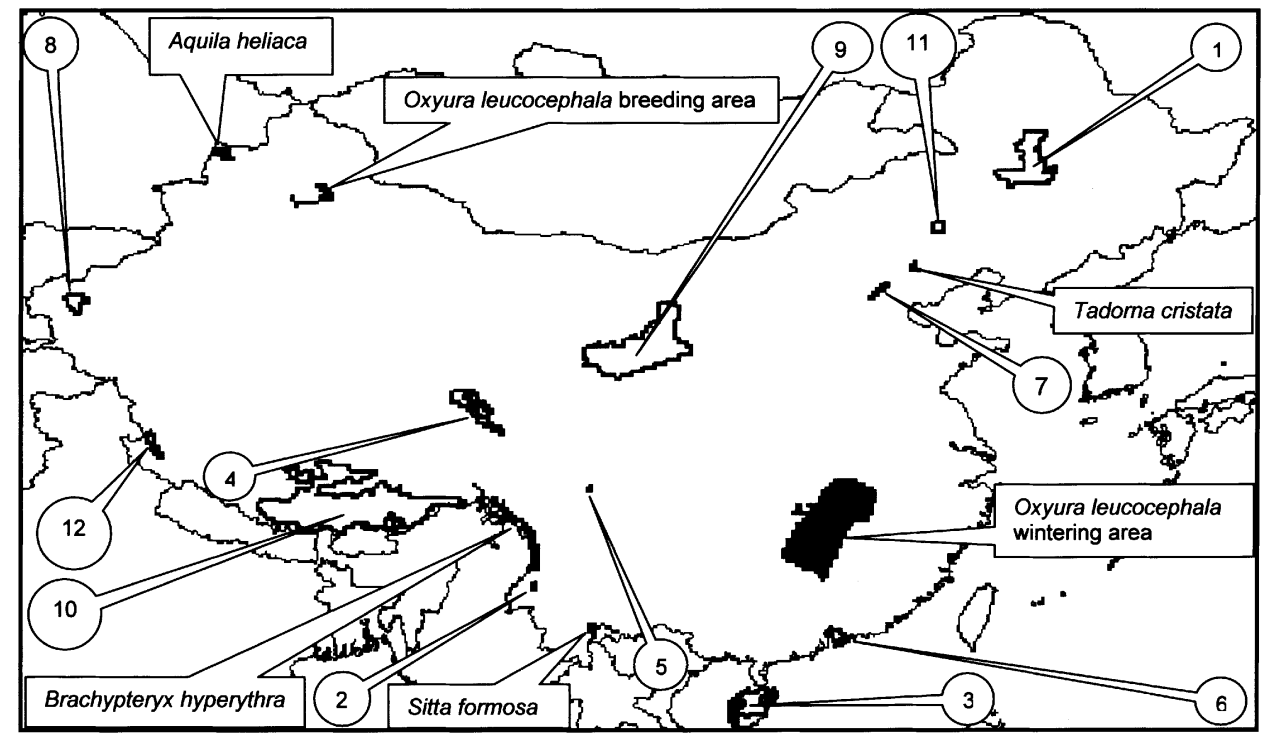

Figure 5. Potential additions to the existing reserve network, based on analysis of 55 species not included in existing reserves, based on the range-centre assumption. Priority areas are indicated in order by numbers, and the six species that do not co-occur with other species are also shown.

\section{Discussion}

Several considerations need to be taken into account concerning the area selection procedure employed. Obviously, the conclusions of this study are only as good as the distributional predictions on which they are based. However, several studies indicate that GARP is a valid approach to predicting the distribution of species (Stockwell and Peterson 2002a, b, Peterson 2001, Godown and Peterson 2000, Peterson et al. 2001, 2002). In general, although statistical tests were not feasible owing to the relatively small amount of occurrence data available, we expect that about $90 \%$ of the models developed and used predict geographical distributions much better than would be expected at random.

The application of complementarity methods to predictive models is also in the early stages of development. Complementarity can produce odd combinations of areas because of its clear emphasis on the most different faunal compositions, and for that reason further area selection procedures have been developed, such as the rarity approach used herein. Application of more complex methodologies (e.g. Williams et al. 1996) in the present example, however, is complicated by the enormous number of pixels under consideration in our analyses, in contrast to the usual applications of such methods (Peterson et al. 2000). Nevertheless, previous applications of our approach (Peterson et al. 2000) have shown clear utility in identifying important areas for conservation action.

The pixel-based area selection (i.e. no attention paid to existing reserves) includes 86 of the 90 species in the first 14 areas (Figure 3), whereas the selection among existing reserves can only protect 62 (any-occurrence assumption) and 37 (range-centre assumption) species, respectively. Curves based on existing reserves 
were asymptotic after 10-11 reserves. Our analysis of unprotected species identified additional areas for exploration as potential next priorities for protection.

Our comparison of pixel-based area selection with those of existing protected areas suffers somewhat from differences of scale. Existing protected areas range as large as $10^{6} \mathrm{ha}$, whereas individual pixels are 37,300 ha each, nearly two orders of magnitude smaller. Hence, this contrast further emphasizes that the pixelbased area-selection approach not only achieves better coverage of species, but also does it much more efficiently per unit area.

\section{Acknowledgements}

Many thanks to Mike Crosby for providing data, and David Stockwell for assistance with analyses. This study was supported by the National Science Foundation.

\section{References}

Austin, M. P., Nicholls, A. O. and Margules, C. R. (1990) Measurement of the realized qualitative niche: environmental niches of five Eucalyptus species. Ecol. Monogr. 60: 161177 .

Bojórquez-Tapia, L., Izuara, I. and Ezcurra, E. (1995) Identifying conservation priorities in Mexico through geographic information systems and modeling. Ecol. Appl. 5: 215-231.

Carpenter, G., Gillison, A. N. and Winter, J. (1993) DOMAIN: a flexible modeling procedure for mapping potential distribution of plants and animal. Biodiv. Conserv. 2: 667-68o.

Chen, G. and Peterson, A.T. (2000) A new technique for predicting distribution of terrestrial vertebrates using inferential modeling. Zool. Res. 21: 231-237.

Cheng, T. H. (1979) Fauna Sinica Aves, 2, Anseriformes. Beijing: Science Press.

Cheng, T. H. (1987) A synopsis of the avifauna of China. Beijing: Science Press.

Csuti, B., Polasky, S., Williams, P. H., Pressey, R. L., Camm, J. D., Kershaw, M., Kiester, A. R., Downs, B., Hamilton, R., Huso, M. and Sahr, K. (1997) A comparison of reserve selection algorithms using data on terrestrial vertebrates in Oregon. Biol. Conserv. 8o: 83-97.

Daniels, R. J. R., Hegde, M., Joshi, N. V. and Gadgil, M. (1991) Assigning conservation value: a case study from India. Conserv. Biol. 5: 464-475.

Environmental Systems Research Institute (ESRI) (1996). ArcAtlas: our Earth. 380 New York Street, Redlands, CA 92373-8100, USA: ESRI.

Godown, M. and Peterson. (2000) Preliminary distributional analysis of US endangered bird species. Biodiv. Conserv. 9: 1313-1322.

Grinnell, J. (1917) Field tests of theories concerning distributional control. Am. Nat. 51: $115-128$.

Harrison, J. A. and Martinez, P. (1995) Measurement and mapping of avian diversity in southern Africa: implications for conservation planning. Ibis 137: 410-417.

IUCN (2000) Red list of threatened species. http://redlist.cymbiont.ca/resultslist. asp.

Kershaw, M., Williams, P. H. and Mace, G. M. (1994) Conservation of Afrotropical antelopes: consequences and efficiency of using different site selection methods. Biodiv. Conserv. 3: 354-372.

Kiester, A. R., Scott, J. M., Csuti, B., Noss, R. F., Butterfield, B., Sahr, K. and White, D. (1996) Conservation prioritization using GAP data. Conserv. Biol. 10: 1332-1342.

MacArthur, R. A. (1972) Geographical ecology. Princeton, NJ: Princeton University Press.

Meyer de Schauensee, R. (1984) The birds of China. Washington, DC: Smithosonian Institution Press. 
Nix, H. A. (1986) A biogeographic analysis of Australian elapid snakes. Pp. 4-15 in Atlas of Australian Elapid Snakes. Canberra: Bureau of Flora and Fauna.

Peters, J. L. (1940) Check-list of birds of the world, I-XVI. Cambridge, MA: Harvard University Press.

Peterson, A. T., Ball, L. G. and Cohoon, K. P. (2002) Predicting distributions of tropical birds. Ibis 144: e27-e32.

Peterson, A. T. and Cohoon, K. P. (1999) Sensitivity of distributional prediction algorithms to geographic data completeness. Ecol. Modeling 117: 159-164.

Peterson, A. T., Egbert S. L., Sánchez-Cordero, V. and Price, K. P. (2000) Geographic analysis of conservation priority: endemic birds and mammals in Veracruz, Mexico. Biol. Conserv. 93: 85-94.

Peterson, A. T. (2001) Predicting distributions of North American birds. Condor 103: 599605.

Peterson, A. T., Soberón, J. and Sánchez-Cordero, V. (1999) Conservatism of ecological niches in evolutionary time. Science 285: 1265-1267.

Peterson, A. T., Stockwell, D. R. B. and Kluza, D. A. (2002) Distributional prediction based on ecological niche modeling of primary occurrence data. In J. M. Scott, ed. Predicting species occurrences: issues of scale and accuracy. Washington, DC: Island Press.

Pressey, R. L., Possingham, H. P. and Margules, C. R. (1996) Optimality in reserve selection algorithms: when does it matter and how much? Biol. Conserv. 76: 259-267.

Russell-Smith, J. and Bowman, D. M. J. S. (1992) Conservation of monsoon rainforest isolates in the Northern Territory, Australia. Biol. Conserv. 59: 51-63.

Salvadori, T. (1895) Catalogue of birds in the British Museum, V-XXVII. London: Taylor and Francis.

Sperduto, M. B. and Congalton, R. G. (1996) Predicting rare orchid (Small Whorled Pogonia) habitat using GIS. Photogr. Eng. and Remote Sens. 62: 1269-1279.

Stockwell, D. R. B. and Noble, I. R. (1992) Induction of sets of rules from animal distribution data: a robust and informative method of data analysis. Math. Comp. Simul. 33: 385390.

Stockwell, D. R. B. and Peters, D. (1999) The GARP modeling system: problems and solutions to automated spatial prediction. Int. J. Geogr. Inf. Sci. 13: 143-158.

Stockwell, D. R. B. and Peterson, A. T. (2002a) Effects of sample size on accuracy in species distribution models. Ecological Modeling 148: 1-13.

Stockwell, D. R. B. and Peterson, A. T. (2002b) Comparison of methods of mapping biodiversity using museum data. In J. M. Scott, ed., Predicting species occurrences: issues of scale and accuracy. Washington, DC: Island Press.

Walker, P. A. and Cocks, K. D. (1991) A procedure for modeling a disjoint environmental envelope for a plant or animal species. Global Ecol. Biogeogr. Lett. 1: 108-118.

Williams, P., Gibbons, D., Margules, C., Rebelo, A., Humphries, C. and Pressey, R. (1996) A comparison of richness hotspots, rarity hotspots, and complementarity areas for conserving diversity of British birds. Conserv. Biol. 10: 155-174.

\section{GUOJUN CHEN and A. TOWNSEND PETERSON ${ }^{1}$}

Natural History Museum, The University of Kansas, Lawrence, KS 66045, USA.

${ }^{1}$ Author for correspondence; e-mail: town@ukans.edu 